\title{
Simulações hidrológicas para apoio a gestão de operação da Barragem do Rio São Bento
}

\author{
Hydrological simulations to support the operation management \\ of São Bento RiverDam
}

\section{Juliano Possamai Della Álvaro José Back}

RESUMO: A região Sul de Santa Catarina apresenta boa parte dos recursos hídricos comprometidos pela poluição devido à mineração do carvão. A escassez de água de boa qualidade aliada à grande demanda, leva a conflitos pelo uso da água. A barragem do rio São Bento foi construída com objetivo de solucionar os problemas de abastecimento de água, bem como atender a demanda de parte da área irrigada e auxiliar no controle de cheias. Os diferentes usos de água são conflitantes, havendo necessidade de estabelecer critérios de operaçáo da barragem e gestáo dos recursos hídricos. Este trabalho teve como objetivo principal a proposição de critérios de operação da barragem do rio São Bento por meio de simulação dos volumes do reservatório sob vários cenários de uso da água. Nestas simulaçōes foram consideradas as situaçóes de reservatório Cheio, Normal, Alerta, Crítico e Falha, estabelecendo o período de retorno de cada situação. Nas simulaçóes observadas constatou-se que o reservatório da barragem do rio São Bento tem possibilidade de atender demandas superiores às atuais.

PALAVRAS-CHAVE:precipitação, reservatório, hidrologia, cadeia de Markov.
Submetido: 05-06-14

Revisão: 27-02-15

Aprovado: 20-05-15

$$
\text { gia, cadeia di }
$$

\section{INTRODUÇÃO}

A região carbonífera catarinense possui grande parte dos rios poluídos pela atividade da mineraçáo de carvão, gerando escassez de recursos hídricos, para o abastecimento e para uso industrial, bem como para a agricultura. Com esta escassez ocorrem conflitos de interesses pela utilização da água, principalmente nos períodos de estiagem. Em função desta problemática,a barragem do rio São Bento se constituiu em uma obra de fundamental importância para o abastecimento humano, industrial e agrícola da região, (CASAN-OAS, 2001). que é agravada pela crescente demanda de água
ABSTRACT: A large part of the water resources of the southern region of Santa Catarina state, Brazil has been compromised by coal mining. The scarcity of good quality water concomitantly with the high demand for it leads to water use conflicts. The São Bento river dam was built in order to solve water supply problems, cover the irrigated area demand and assist in flood control. There is conflict among different water uses, and it is necessary to establishs dam operation and water resources management criteria. This article aimed to propose some criteria for operating São Bento river dam by simulating reservoir volumes under different water use scenarios. In these simulations, the reservoir was considered as Full, Regular, Warning, Critical, and Failure conditions, establishing the return period of each situation. The simulations showed that the Sao Bento River dam reservoir can cover higher demands than the current ones.

KEYWORDS: precipitation, reservoir, hydrology, Markov chain.
A barragem do rio São Bento foi projetada para atender três finalidades principais que eram o abastecimento, a irrigaçáo e o controle de cheias. No entanto, estes usos são conflitantes e por isso há necessidade de estabelecer critérios para a operação da barragem, de forma a atender de modo racional as diferentes demandas. Na política básica de operação da barragem foram criadas situaçôes de normal, atenção e emergência tanto para períodos de cheias quanto para períodos de estiagem (CASAN, 2004). No entanto, não foram estabelecidos critérios de distribuição da água e as quantidades para cada segmento a ser atendido.

Nos quase dez anos de operação da barragem, foram registrados mais de cem vertimentos, evidenciando que 
ocorrem frequentes períodos com excessos água. Essa aparente abundância de água pode sugerir aumentar a oferta de água, tanto para consumo humano como para a irrigação. Assim, é de grande importância estudos que possam demonstrar os riscos de falha no atendimento dessas demandas em função dos usos destinados.

Por outro lado, no período de operação da barragem também ocorreram algumas estiagens, que embora de curta duração, foram suficientes para gerar conflitos e pressão pela maior oferta da água, principalmente por parte dos rizicultores. Quando da ocorrência da maior estiagem, verificada em dezembro de 2012, o nível mínimo da barragem atingiu o volume correspondente a 55,36\% da capacidade máxima do reservatório. Nesta ocasião, visualizando a diminuição da área alagada, a população ficou apreensiva quanto aos riscos de falta de água.

A gestão dos recursos hídricos deve ser realizada com base em estudos e informaçôes sobre os riscos envolvidos no processo e requer que os critérios para a operação da barragem estejam definidos e acordados entre os usuários.

Para a melhor utilização e otimização deste recurso é fundamental a utilização de ferramentas de gestão dos recursos hídricos. Segundo Azevedo et al. (1997), a crescente complexidade dos problemas de planejamento e gestão de recursos hídricos, principalmente durante situaçóes de escassez quantitativa ou qualitativa de água, requer a utilização de técnicas e instrumentos capazes de auxiliar profissionais responsáveis pela análise, operaçáo, planejamento e tomada de decisão em recursos hídricos

Vários modelos de operação e dimensionamento de reservatórios foram desenvolvidos e empregados para o gerenciamento de recursos hídricos (YEH, 1985; WURBS, 1993; LABADIE, 2004; VAN OEL et al., 2008; CAMPOS, 2010). Estes modelos podem ser de otimização ou de simulação. Segundo Tucci (1988) a otimização é a busca do valor de uma ou mais vaiáveis, que proporcionem o melhor resultado para uma função dependente destas variáveis, dentro de um objetivo e obedecendo a restriçóes. Os métodos tradicionais de otimização aplicados a problemas de planejamento e gerenciamento de recursos hídricos incluem programação linear, programação não linear, programação dinâmica e otimização em fluxo de rede. Exemplos de aplicação de modelos de otimizaçáo podem ser obtidos em de Becker; Yeh (1974), Mohammadi; Mariño (1984), Barbosa (1986), Mohan; Raipure (1992), Cirilo (2002).

Os modelos de simulação se diferenciam pelo fato de que não determinam a política ótima de operação do reservatório. Conforme Peixoto (2006), a simulação é considerada uma das melhores alternativas para avaliar os conflitos causados pelo uso múltiplo na gestáo de sistema de recursos hídricos. $\mathrm{O}$ modelo de simulaçáo fornece a resposta de um sistema a um conjunto de informaçáo de entrada, que incluem regras de decisão, permitindo ao usuário examinar as consequências de diversos cenários de um sistema existente ou de um sistema existente ou de um sistema em projeto. Os resultados do modelo incluem índices estatísticos e funçóes de probabilidade que indicam o nível com que os objetivos da operaçáo do sistema foram satisfeitos. Vários trabalhos (BRAGA, 1987; LAW; BROWN, 1989; FRAVERT et al., 1994; AZEVEDO et al., 2000; AZAMBUJA, 2000; PEIXOTO, 2002; LIMA, 2002) foram realizados com modelo de simulação de reservatórios.

Sistemas de Suporte à decisão são constituídos por um espectro mais ou menos amplo de modelos matemáticos (simulação e otimização da gestáo), base de dados, sistemas de informação geográfica e bases de conhecimentos. Os sistemas de suporte a decisão podem contribuir e facilitar a tomada de decisão em épocas de secas, nas quais aparecem conflitos pelo uso do recurso, permitindo aos implicados avaliar os riscos assumidos no futuro como consequências das decisóes de utilizaçáo de água. Estes modelos foram aplicados por Andreu et al. (1996), Eschenbach et al. (2001) e Maia et al. (2001)

Por se caracterizar como uma obra de múltiplos usos, a barragem do rio São Bento foi projetada com a finalidade proporcionar uma vazão regularizada atendendo com segurança as demandas de abastecimento urbano, irrigação de áreas cultivadas a jusante além da manutençáo da vazáo ecológica. Posteriormente foi incluído entre as finalidades da barragem o controle de cheia. A proposição dos critérios de operação da barragem para atender os múltiplos usos de forma mais racional se constitui numa contribuição para o gerenciamento racional dos recursos hídricos da barragem do rio São Bento.

Este trabalho teve como objetivo realizar simulaçóes do volume de água armazenado no reservatório da Barragem do Rio São Bento com diferentes demandas de água para abastecimento e irrigação estimando os riscos de atendimento às demandas pré estabelecidas.

\section{MATERIAIS E MÉTODOS}

A barragem do rio São Bento, localizada no estado brasileiro de Santa Catarina no município de Siderópolis, está inserida na bacia hidrográfica do rio São 
Bento sendo definida como uma sub-bacia da bacia hidrográfica do rio Araranguá.

O reservatório possui uma área de inundação no nível máximo normal (cota $137,5 \mathrm{~m}$ ) de 450 ha e uma área de drenagem a montante de $112,12 \mathrm{~km}^{2}$. A capacidade do reservatório é de $58,5 \mathrm{hm}^{3}$ e o volume morto de $1,4 \mathrm{hm}^{3}$ (Figura 1).

A composição das estruturas do empreendimento se caracteriza em três obras distintas. A barragem principal, caracterizada como mista de concreto compactado a rolo (CCR) do tipo gravidade no centro e nas ombreiras de enrocamento com espaldares em cascalho compactado com núcleo impermeável de argila. As obras complementares são duas barragens do tipo zoneado com núcleo em argila compactada e espaldares em cascalho.

A bacia hidrográfica do rio São Bento possui forma arredondada tipo leque a montante da barragem principal e estendida com forma retangular à jusante. A vazão média é da ordem de $3,12 \mathrm{~m}^{3} \cdot \mathrm{s}^{-1}$, possuindo como máxima mensal média de $23,15 \mathrm{~m}^{3} . \mathrm{s}^{-1}$ e média da mínima mensal de $0,83 \mathrm{~m}^{3} \cdot \mathrm{s}^{-1}$ (CASAN, 2003).

Conforme Casan (2004), o clima onde está localizada a bacia hidrográfica em estudo, segundo o sistema de classificação de Köppen, é do tipo Cfa (clima

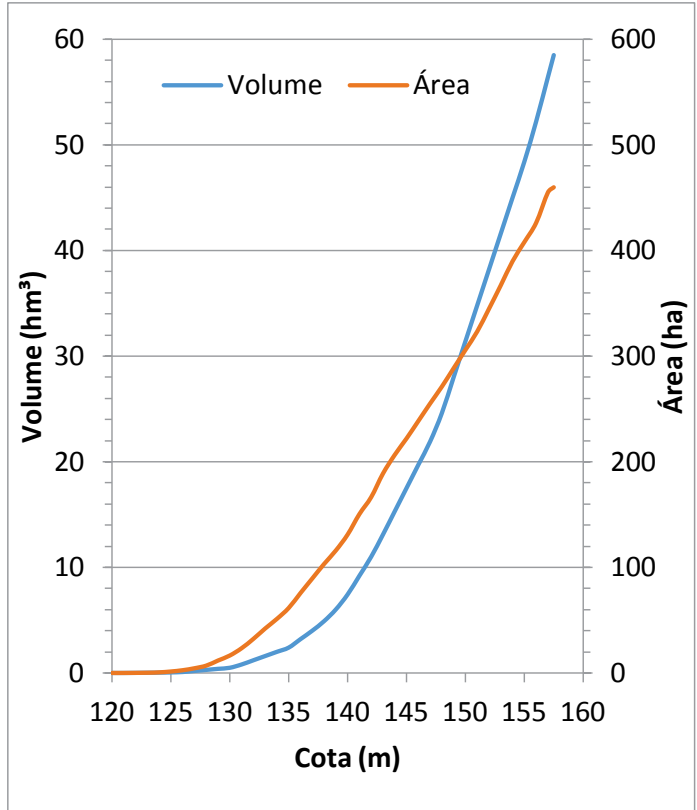

FIGURA 1. Relação Cota $x$ Volume e Cota $x$ Área da barragem do Rio São Bento. subtropical úmido), temperado moderado chuvoso. A distribuição sazonal da precipitação é caracterizada com 36\% da precipitaçáo ocorrendo no veráo, $23,5 \%$ no outono e primavera e com apenas $17 \%$ da precipitação ocorrendo no inverno. Back et al. (2011) afirmam que a precipitação total anual na regiâo Sul de Santa Catarina, varia de 1220 a 1660 mm, com o total anual de dias de chuva entre 98 e 150 dias.

No modelo de balanço hídrico foi considerada como entrada de água a vazão afluente bem como a precipitação direta na área do reservatório. As saídas de água foram dadas pela vazão ecológica, evaporação, demanda de água para consumo humano e a demanda de água para irrigação.

Os procedimentos metodológicos usados neste estudo encontram-se na Figura 2. A etapa inicialconsistiu na coleta e organizaçáo dos dados. A segunda etapa do estudo consistiu na geração das séries de chuva e vazóes afluentes. A terceira etapaconsistiu na criação dos cenários de demanda hídrica e análise do balanço hídrico do reservatório. $\mathrm{O}$ cenário inicial (cenário1) representa a situação atual das demandas da barragem, dado pela demanda de abastecimento de uma população de 300.000 habitantes, irrigação de 6.000 ha de cultivos de arroz e a vazão ecológica de $100 \mathrm{~L} / \mathrm{s}$, conforme estabelecido pelo

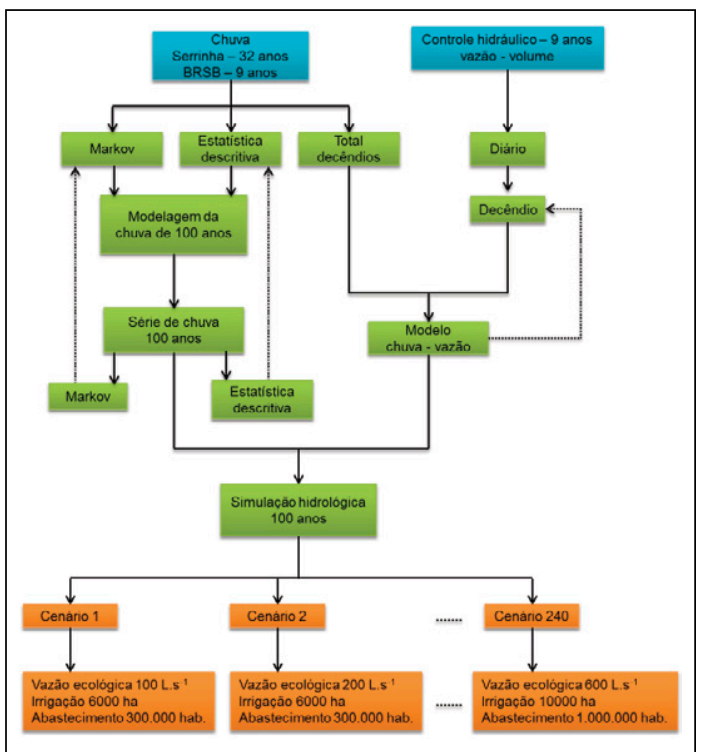

FIGURA 2. Fluxograma da metodologia utilizada. 
órgão ambiental (CASAN, 2004). Foram elaborados vários cenários considerando as combinaçóes das demandas de abastecimento para população crescente até 1.000.000 de habitantes e também ampliação da área irrigada com cultivo de arroz a jusante da barragem de até 10.000 ha. Como a vazão ecológica é questionada pelo baixo valor, também foram considerados valores de vazão ecológica de até $600 \mathrm{~L} / \mathrm{s}$. Nestas simulaçóes não foram considerados critérios para controle de cheias, uma vez que este efeito sempre ocorre quando o volume do reservatório está abaixo do nível máximo. Dessa combinação resultaram 240 diferentes cenários, em que o cenário mais crítico é dado pelo demanda de abastecimento de uma populaçáo de 1.000 .000 habitantes, irrigação de 10.000 ha de cultivos de arroz e a vazão ecológica de $600 \mathrm{~L} / \mathrm{s}$ (Figura 2).

Foram usados os dados diários de precipitação da estação meteorológica da barragem dorio São Bento, comdados do período de 2004 a 2013. Também foram utilizados os dados da Estação Pluviométrica da Serrinha, pertencente à Agência Nacional de Águas (ANA, 2009), código 84800000, latitude 28³6'44" e longitude 49०33'04”.

Dos registros do controle hidráulico do reservatório da barragem do rio Sáo Bento foram obtidos os dados para a determinação do balanço hídrico do reservatório, como a vazáo afluente e vazão defluente, que ocorre pelos descarregadores de fundo, válvula dispersora, adução para abastecimento e vazão do vertedouro.

Um modelo mais simples para estimar o volume afluente a partir da chuva consistiu em multiplicar o volume da precipitação por um coeficiente empírico, equação (1).

$$
Q=P x C
$$

Para ajustar este modeloforam utilizados os dados registros dos oito anos de operaçáo da barragem do rio São Bento e também os dados de precipitação da estação Serrinha (ANA, 2009), localizada a jusante da barragem. Com os dados diários de chuva agrupados em decêndios e posteriormente transformada em volume, juntamente com os dados de vazão do reservatório foi ajustado o parâmetro de escoamento "C" para a bacia.

Para a determinação das vazóes afluentes foi gerada uma série de dados de precipitaçáo com 100 anos de duração, e posteriormente com esses dados de precipitação foram obtidas às vazôes afluentes.

$\mathrm{Na}$ modelagem da ocorrência de precipitação foi considerada a cadeia de Markov de dois estados, em que o dia é considerado seco ou chuvoso. O critério adotado para dia ser seco foi de chuva inferior a 1,0 $\mathrm{mm}$. Neste trabalho foi utilizada a cadeia de primeira ordem, em que a probabilidade de um dia ser seco (ou chuvoso) depende somente da condiçáo do dia anterior (ARAÚJO et al, 2012).

Para levar em conta a estacionariedade, os parâmetros do modelo foram ajustados por períodos mensais. Dessa forma foram determinadas as matrizes de probabilidades de transição conforme:

$$
\begin{gathered}
P_{00 i}=\frac{N_{00 i}}{N_{00 i}+N_{01 i}} \\
P_{10 i}=\frac{N_{10 i}}{N_{10 i}+N_{11 i}} \\
P_{01 i}=1-P_{00 i} \\
P_{11 i}=1-P_{10 i}
\end{gathered}
$$

em que:

$\mathrm{P}_{00}=$ Probabilidade de um dia ser seco, dado que o anterior também foi seco;

$\mathrm{P}_{10}=$ Probabilidade de um dia ser seco, dado que o anterior foi chuvoso;

$\mathrm{P}_{01}=$ Probabilidade de um dia ser chuvoso, dado que $\mathrm{o}$ anterior foi seco;

$\mathrm{P}_{11}=$ Probabilidade de um dia ser chuvoso, dado que $\mathrm{o}$ anterior foi chuvoso;

$\mathrm{N}_{10}=$ freqüência observada da seqüência de dia chuvoso seguido por dia seco;

$\mathrm{N}_{11}$ = freqüência observada de seqüência de dois dias chuvosos;

$\mathrm{N}_{00}=$ freqüência observada da seqüência de dois dias secos;

$\mathrm{N}_{01}$ = freqüência observada de um dia seco seguido por dia chuvoso;

$\mathrm{i}=$ mês (1 a 12).

Para a simulação da quantidade de chuva nos dias chuvosos foram testadas as distribuiçóes exponencial e gama conforme descrito em Silva et al. (2013). Com este modelo ajustado foi gerada uma série com 100 anos de dados de precipitaçáo diária, que posteriormente foi convertida em vazóes decendiais.

A simulação do reservatório foi realizada com base no balanço hídrico em intervalo decendial dado através da equação (6): 


$$
\begin{aligned}
S_{t}=S_{t-1}+P & +Q_{a}-E-Q_{e c o} \\
& -Q_{i r r}-Q_{c o n s}
\end{aligned}
$$

em que:

$S_{t}=$ armazenamento no decêndio $t\left(\mathrm{~m}^{3}\right)$,

$\mathrm{S}_{\mathrm{t}-1}=$ armazenamento no mês decêndio $\left(\mathrm{m}^{3}\right)$,

$\mathrm{P}=$ precipitaçáo direta no lago $\left(\mathrm{m}^{3}\right)$,

$\mathrm{Q}_{\mathrm{a}}=$ vazão afluente $\left(\mathrm{m}^{3}\right)$,

$\mathrm{Q}_{\text {eco }}=$ vazão ecológica $\left(\mathrm{m}^{3}\right)$,

$\mathrm{Q}_{\text {irr }}=$ vazão para irrigação $\left(\mathrm{m}^{3}\right)$,

$\mathrm{Q}_{\text {cons }}=$ vazão para consumo humano $\left(\mathrm{m}^{3}\right)$,

$\mathrm{E}=$ evaporação $\left(\mathrm{m}^{3}\right)$.

Considerando que não existem critérios definidos para a operação da barragem, foram criadas situaçóes do reservatório, classificando como: Cheio, Normal, Alerta, Crítico e Falha. Nas simulaçôes foram avaliadas as frequências de ocorrência no decêndio de cada uma destas classes. As situaçóes foram definidas de forma arbitráriacomo:

Cheio: para volumes acima de $58,50 \mathrm{hm}^{3}$ (cota $157,50 \mathrm{~m}$ ) onde ocorre o vertimento dos volumes excedidos pelo reservatório;

Normal: para volumes entre $29,00 \mathrm{hm}^{3}$ (cota $149,30 \mathrm{~m})$ e $58,50 \mathrm{hm}^{3}(\operatorname{cota} 157,50 \mathrm{~m})$;

Alerta: para os volumes compreendidos entre $14,50 \mathrm{hm}^{3}(\operatorname{cota} 143,64 \mathrm{~m})$ e $29,00 \mathrm{hm}^{3}$ (cota $149,30 \mathrm{~m})$;

Crítico: para os volumes compreendidos entre $1,4 \mathrm{hm}^{3}$ (cota 132,50 m) localização da última comporta de abastecimento da adutora e $14,50 \mathrm{hm}^{3}$ (cota 143,64 m);

Falha: para volumes inferiores a $1,4 \mathrm{hm}^{3}$, nível este compreendido na soleira da última comporta de adição.

\section{RESULTADOS E DISCUSSÃO}

Constata-se que as séries observadas e simuladas (Figura 3) apresentaram valores das probabilidades de transição praticamente iguais, indicando dessa forma que o modelo ajustado irá simular séries de chuva com sequências de dias secos e chuvosos semelhantes ao período observado.

Mesmo com o efeito da sazonalidade o comportamento apresentou resultados satisfatórios demonstrando pequena distorção para o dia com chuva seguido de dia seco $\left(\mathrm{P}_{10}\right)$ na série observada e simulada nos meses de março e maio. Essas diferenças podem em parte ser atribuídas às falhas nas observaçóes da série observada.

Uggioni e Back (2005) analisando dados de várias estaçôes pluviométricas do Sul de Santa Catarina também concluíram que com o modelo de Markov de primeira ordem de dois estados a simulaçáo das sequências de dias secos e chuvosos entre as séries observadas e simuladas preserva as mesmas características.

Os totais mensais de precipitação da série observada e das séries obtidas com a distribuição exponencial e distribuição gama, chamando neste trabalho de série simulada, apresentaram variação de valor insignificante para os estudos realizados, demonstrando bom comportamento das séries simuladas (Figura 4). Verifica-se também a marcante distribuição sazonaldas precipitaçôes, com maior ocorrência das precipitaçóes nos meses de janeiro a março. Também não foram encontradas diferenças significativas entres frequências dos totais anuais de precipitação simulada com a distribuição exponencial e distribuição gama (Figura 5).

Modelos hidrológicos do tipo chuva-vazão são ferramentas úteis na análise da disponibilidade de água em bacias hidrográficas. Collischonn et al. (2011) destacam que uma dificuldade importante na aplicaçáo deste tipo de modelos é a necessidade

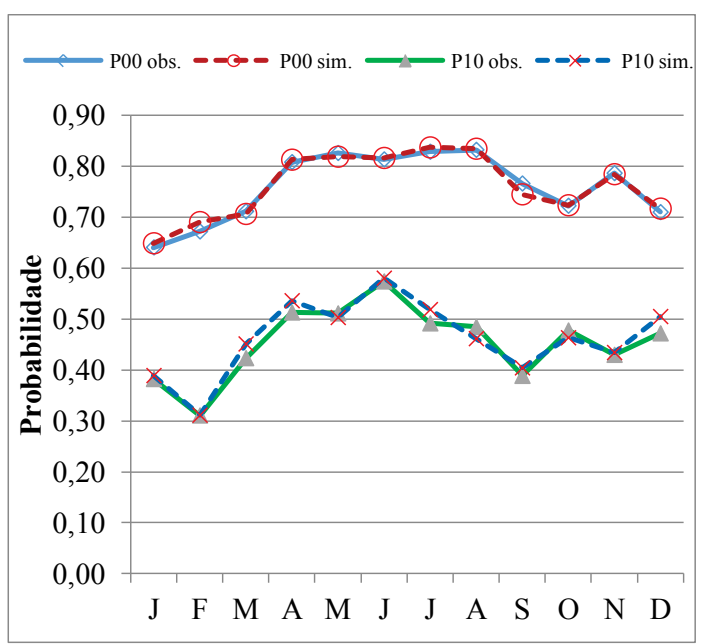

FIGURA 3. Variação sazonal dos parâmetros da cadeia de Markov da série observada (obs.) e simulada (sim.). 
de definir valores de parâmetros do modelo com base em séries observadas de chuva e de vazão. No modelo utilizado neste estudo foi necessário realizar a calibração do coeficiente $\mathrm{C}$ com base nos dados do controle hidráulico da barragem. Para o modelo

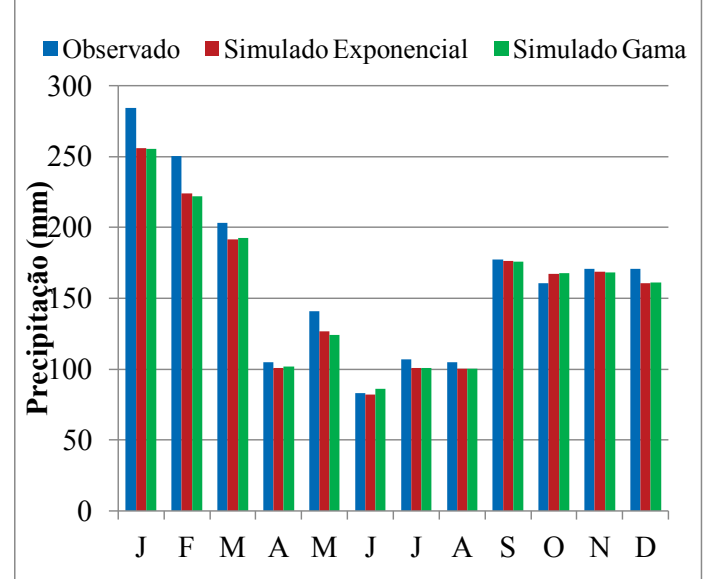

FIGURA 4. Totais mensais de precipitação da série observada e simuladas com a distribuição exponencial e distribuição gama.

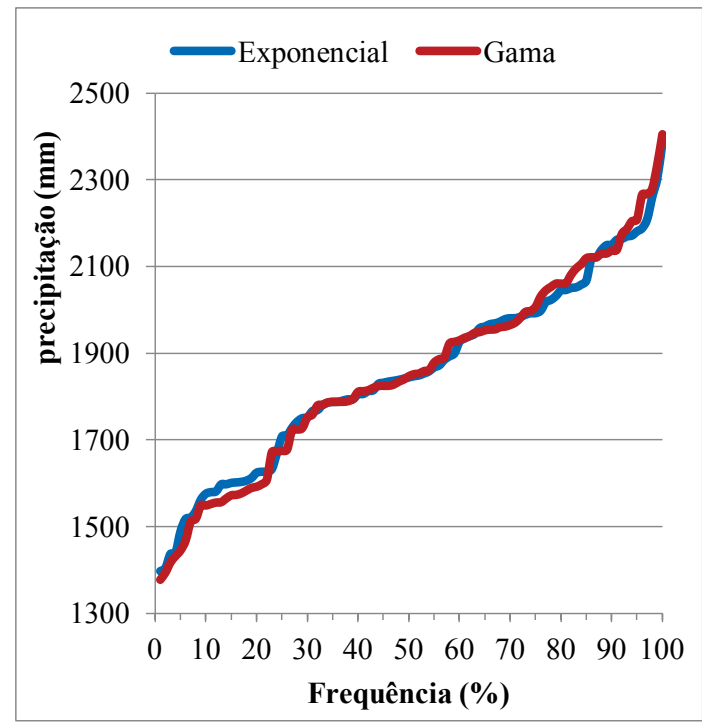

FIGURA 5. Frequência de precipitação total anual simuladas com as distribuições exponencial e gama. chuva-vazão ajustado foi considerado de resultado satisfatório, com pequenas diferenças entre os valores observados e simulado no volume do reservatório no período de 2004 (Figura 6) a 2012 (Figura 7). Obteve-se um coeficiente $\mathrm{C}$ médio de 0,7 , valor que

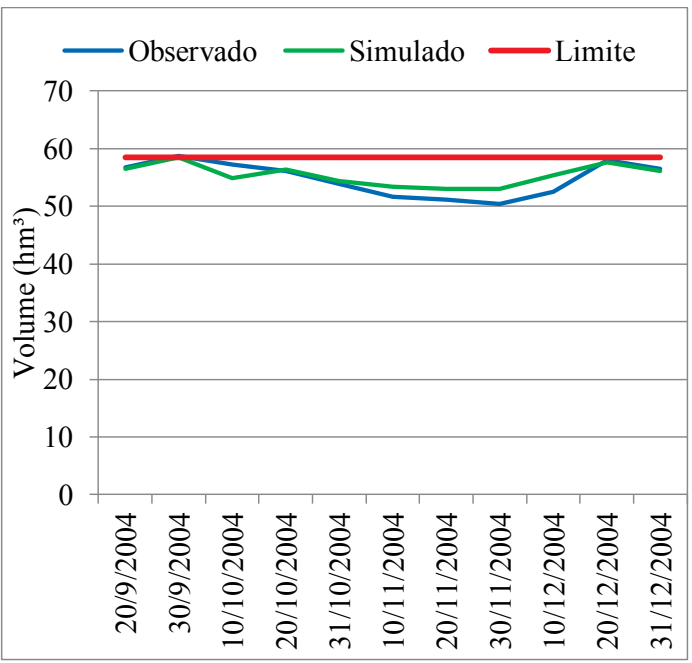

FIGURA 6. Variação do volume do reservatório observado e simulado no período de 2004.

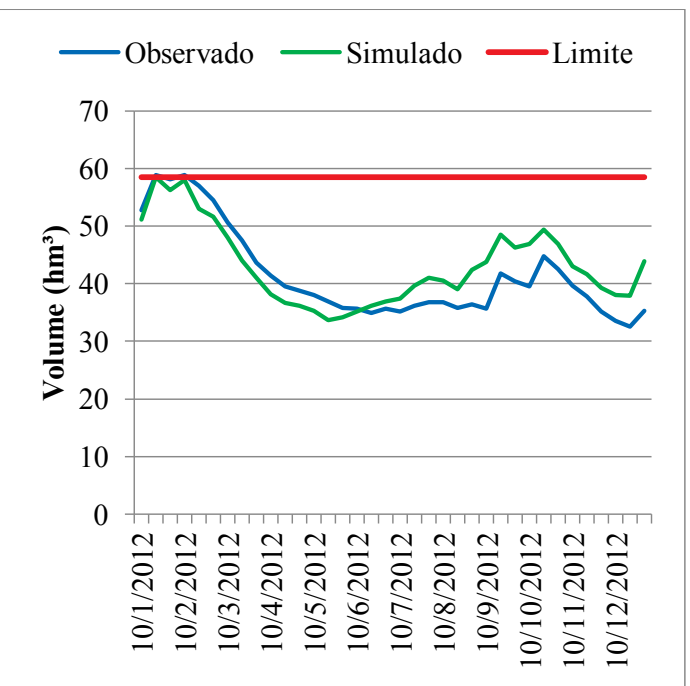

FIGURA 7. Variação do volume do reservatório observado e simulado no período de 2012. 
é considerado alto. Segundo Collischonn e Dornelles (2013) o coeficiente de escoamento para maioria das bacias hidrográficas brasileiras varia de 0,1 a 0,5 . O valor mais alto encontrado neste estudo pode ser explicado por alguns fatores. O primeiro fator é a área da bacia, que é muito pequena em relação às bacias citadas pelos autores. Em pequenas bacias o coeficiente de escoamento tende a ser maior. Um segundo fator é a geomorfologia da bacia da barragem do rio São Bento, caracterizada pela alta declividade, solos rasos sobre rochas, que favorecem o escoamento superficial e a maiores valores de coeficiente C. Um terceiro e importante fator é o efeito orográfico sobre a precipitação uma vez que existem vários trabalhos que mostram que nas cabeceiras dos rios e na encosta da serra a precipitação pluviométrica é significativamente superior à precipitaçáo registrada a jusante.

No estudo de Regionalização Hidrológica de Santa Catarina (SANTA CATARINA, 2006) os valores de coeficiente de escoamento $\mathrm{C}$ das bacias hidrográficas dos principais cursos d'água de Santa Catarina, variaram de 0,25 a 0,81. Para as bacias hidrográficas com formação geológica e clima semelhantes à bacia de contribuição da barragem do rio São Bento, no estudo de Regionalizaçáo Hidrológica são citados valores de $\mathrm{C}=0,80$ (Rio Manoel Alves com área

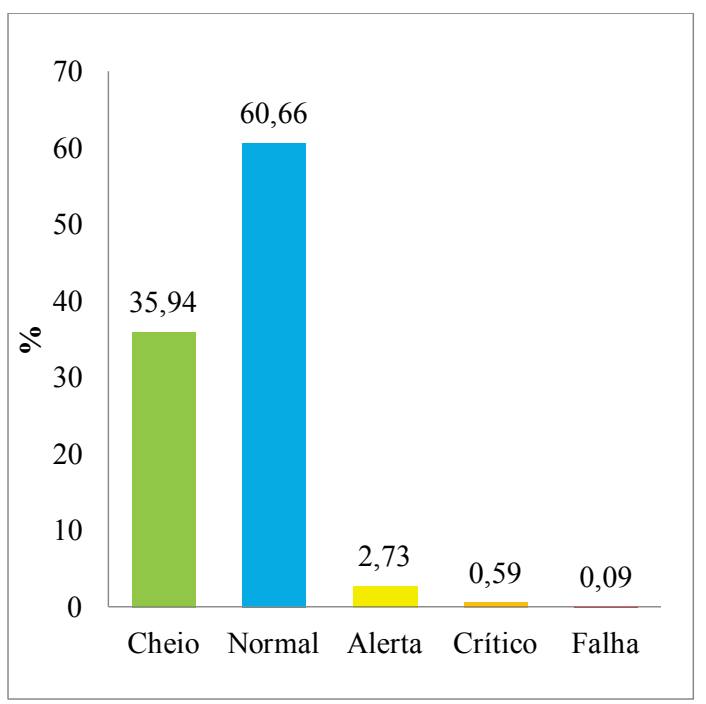

FIGURA 8. Percentual das situações encontradas. de $338 \mathrm{~km}^{2}$ ), $\mathrm{C}=0,79$ (rio Amola Faca com área de $303 \mathrm{~km}^{2}$ ), $\mathrm{C}=0,81$ (Rio Itoupava com área de $817 \mathrm{~km}^{2}$ ), $\mathrm{C}=0,70$ (Rio Mãe Luzia com área de $520 \mathrm{~km}^{2}$ ). Estes valores mostram que o parâmetro C ajustado está coerente com as características hidrológicas da área em estudo.

$\mathrm{Na}$ Figura 8 consta o resumo das frequências percentuais de ocorrência dos volumes do reservatório nas diferentes condiçóes, para as simulaçóes com os 240 cenários. Verifica-se que 35,94 \% dos decêndios o reservatório está na situação Cheio, e 60,66\% em nível Normal, e somente 3,41\% dos decêndios a condição era de Alerta ou Crítica ou de Falha. Esses resultados mostram que, de forma geral, a barragem do rio São Bento pode atender as demandas com risco de falhas de atendimento muito baixo.

$\mathrm{Na}$ Figura 9 encontram-se representados os períodos de retorno para a condição Crítica em função da demanda para abastecimento da população (habitantes) e da área irrigada com rizicultura (ha).

Para área de 6000 ha esta condição nunca foi observada, e para área de 7000 ha somente ocorre para a população de um milhão de habitantes, com duas ocorrências na série de 100 anos simulados, indicando assim período de retorno de 50 anos. Para área de 8000 ha a condição Crítica somente ocorre

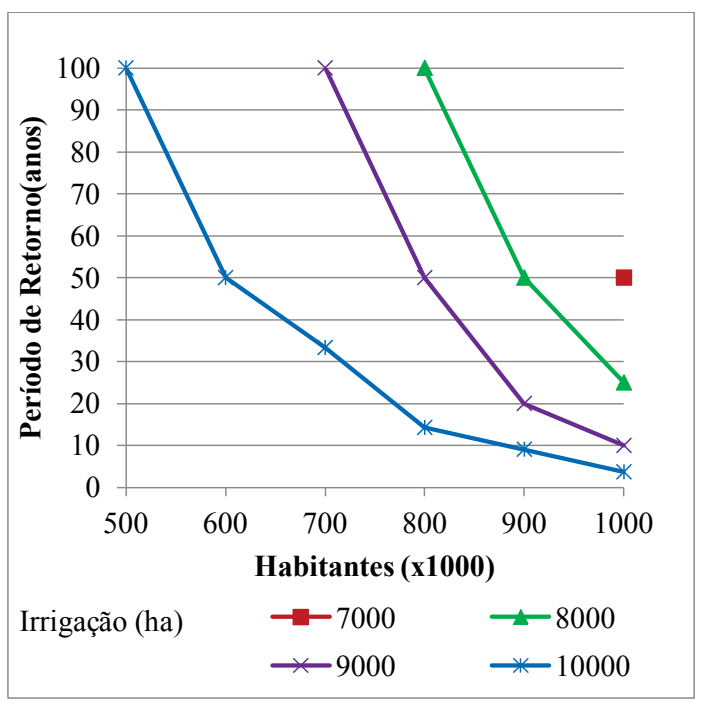

FIGURA 9. Período de retorno para a condição de Crítica em função da demanda para abastecimento da população (habitantes) e da área irrigada com rizicultura (ha). 
para população superior a 800 mil habitantes. Para a demanda de irrigação de 9000 ha, a condição Crítica é verificada para população acima de 700 mil habitantes enquanto que para a área irrigada de 10000 ha a situação Crítica ocorre para população acima de 500 mil habitantes. Na situação Crítica a critério de gerenciamento da barragem deveria suspender a irrigação de forma a preservar a água para o abastecimento humano.

A condição de Falha do reservatório considerando a vazão ecológica de $100 \mathrm{~L} . \mathrm{s}^{-1}$, somente foi observada no cenário com a demanda extrema para abastecimento da população de 1.000 .000 de habitantes e irrigação de 10000 ha. $\mathrm{Na}$ série simulada com 100 anos esta condição de Falha ocorreu 6 vezes, indicando período de retorno de 16,67 anos. A Falha no reservatório indica que o volume armazenado não foi suficiente para atender toda a demanda prevista e é a condição que se quer evitar.

Esses resultados obtidos confirmam que o reservatório da barragem do rio São Bento tem potencial para atender a demanda atual e futura de água para a população bem como para a irrigação das áreas agrícolas. Nestas simulaçôes foram criados cenários considerando a demanda atual projetada e também cenários mais extremos para avaliar a capacidade de abastecimento da barragem do rio São Bento. Mesmo nos cenários mais críticos o risco de falha é relativamente baixo.

É importante ressaltar que somente foi analisada a condição do volume de água, sem levar em consideração a qualidade da água. Sabe-se que quando o reservatório se encontra em níveis mais baixos a qualidade da água diminui, fato que pode aumentar os custos do sistema de tratamento da água.

\section{CONCLUSÃO}

Com base nos resultados obtidos da análise dos dados hidrológicos e do controle hidráulico da barragem bem como no estudo de simulaçóes realizadas com diferentes cenários usados neste estudo pode-se obter as seguintes conclusôes:

A modelagem matemática da precipitação por meio da cadeia de Markov de primeira ordem com dois estados simulou as sequências de dias secos e chuvosos de acordo com a série observada;

As séries de dados de precipitação simulada com distribuição exponencial e distribuição gama apresentaram as estatísticas semelhantes a série observada e podem ser usadas para obtenção de longas séries de precipitação;

O modelo para geração de série de vazóes adotado embora muito simplificado permitiu simular vazóes afluentes semelhantes com as vazóes obtidas do controle hidráulico da barragem;

O valor coeficiente de escoamento (C) obtido pela vazão afluente do controle hidráulico e da precipitação registrada da estação meteorológica da barragem foi de 0,76 .

A simulação hidrológica é uma ferramenta importante para auxiliar no planejamento e gestão dos recursos hídricos, permitindo avaliar os riscos de falhas no atendimento das demandas sob diferentes cenários;

Nas condiçôes de demanda atual da barragem do rio São Bento a simulação mostrou que o nível do reservatório sempre permanece dentro da situação Normal, com mais de 50\% do volume armazenado;

O reservatório da barragem do rio São Bento mostrou que existe a possibilidade de atender demandas superiores as atuais, e que a adoção de critérios de operaçáo diferenciados podem determinar o melhor uso dos recursos hídricos;

O critério proposto para uso da água pode considerar atender a irrigação em toda a demanda até a situação Normal (acima de 50\%) do volume, reduzindo a demanda da irrigação pela metade quando está no estado de Alerta (de 25 a $50 \%$ do volume) e por fim cancelar a demanda pela irrigação sempre que a situação entre na faixa Crítica (menos de 25 $\%$ do volume).

\section{Referências}

AGÊNCIA NACIONAL DE ÁGUAS. Inventário das estações pluviométricas. Brasília: ANA - SGH, 2009. 332 p.

ANDREU, J.; CAPILLA, J.; SANCHIS, E. AQUATOOL, a generalized decision-support system for water-resources planning and operational management.JournalofHydrology, v.177, n.4, p.269-291, 1996.

ARAÚJO, W.S.; SOUZA, F.A.;BRITO, J.I.B.; LIMA, L.M. Aplicação do modelo estocástico cadeia de Markov a dados diários de precipitação dos Estados da Bahia e Sergipe. Revista Brasileira de Geografia Física, n.3, p. 509-523, 2012. 
AZAMBUJA, C. Disponibilidade hídrica da bacia do rio Piracicaba. Tese (Mestrado) Departamento de hidráulica e Saneamento, Escola de Engenharia de São Carlos. 2000. 180p.

AZEVEDO, L.G.T.; PORTO, R.L.L; FILHO, K.Z. Modelos de simulação e de rede de fluxo. In: PORTO, R.L.L. (org): Técnicas quantitativas para gerenciamento de recursos hídricos. 2ªed, Editora da Universidade, ABRH, Porto Alegre, 1997.

AZEVEDO, L.G.T.; GATES, T.K.; FONTANE, D.G.; LABADIE, J.W.; PORTO, R.L.L. Integration of water quantify and quality in strategic river basin planning. Journal of water resources planning and management, v.126, n.2, p.85-97, 2000.

BACK, A.J.;UGGIONI, E.; VIEIRA, H.J. Modelagem da precipitação de curta duração por meio do modelo de pulsos retangulares de Bartlett-Lewis modificado. Revista Brasileira de Meteorologia, Criciúma, v.26, n.3, p.461-472, mar. 2011.

BARBOSA, P.S.F. Modelos de Programação linear em recursos hídricos. In: Porto, R.L.L.(org) Técnicas quantitativas para gerenciamento de recursos hídricos. $2^{\mathrm{a}}$ ed. Ed Universidade/UFRGS; ABRH, Porto Alegre, p.97-163, 2002.

BECKER, L.; YEH, W. Optimization of Real Time Operation of a Multiple System. WaterResourcesResearch, v.10, n.6, p.1107-1112, 1974. BORSOI, Z.M.F.; TORRES, S.D.A. A política de recursos hídricos no Brasil. Revista do BNDES, Rio de Janeiro, v.4, n.8, p. 143-166, 1997. BRAGA, B.P.F. Técnicas de otimização e simulação aplicadas em sistema de recursos hídricos. In: Modelos de Gerenciamento de Recursos Hídricos. Coleção ABRH de Recursos hídricos, v.1, Nobel. 1987.

CAMPOS, J.N.B. Modeling the Yield-Evaporation-Spill in the Reservoir Storage Process: the Regulation Triangle Diagram. WaterResources Management, v.24, p.3487-3511, 2010.

CASAN (MOR) - Companhia Catarinense de Águas e Saneamento. Manual de operação do reservatório: Barragem do rio São Bento. Santa Catarina, 2003, Relatório Técnico.

. Programa de gerenciamento de risco da barragem São Bento. Santa Catarina, 2004. Relatório Técnico.

CASAN (OAS) - Companhia Catarinense de Águas e Saneamento. Projeto Executivo - Volume 1 - Memorial Descritivo. Siderópolis, SC, 2001, $110 \mathrm{p}$.

CIRILO, J.A. Programação Não-linear Aplicada a Recursos Hídricos.In: Porto, R.L.L.(org) Técnicas quantitativas para gerenciamento de recursos hídricos. $2^{\text {a }}$ ed. Ed Universidade/UFRGS; ABRH, Porto Alegre, p.305-359, 2002.

COLLISCHONN, B.; PAIVA, R.C.D.; COLLISCHONN, W.; MEIRELLES, F.S.C.;SCHETTINI, E.B.C.; FAN, F.M. Modelagem hidrológica de uma bacia com uso intensivo de água: caso do Rio Quaraí-RS. Revista Brasileira de Recursos Hídricos, v.16, n.4, p.119-133, 2011.

COLLISCHONN, W.; DORNELLES, F. Hidrologia para engenharia e ciências ambientais. Porto Alegre: Associação Brasileira de Recursos Hídricos (ABRH), 2013. 336p.

ESCHENBACH, E.A.; MAGEE, T.; ZAGONA, E. GORANFLO, M.; SHANE, R. GoalProgrammingDecisionSupport Systems for MultiobjetiveOperationofReservoir Systems. Journal of Water Resources Planning and Management, v.127, n.2, p.108-120, 2001.

FREVERT, D.K.; LABADIE, J.W; LARSON, R.K.; PARKER, N.L. Integration of water rights and network flow modeling in the Upper Snake River basin. In> 21 st Annual Conference, Water Resources Planning and Management Div., ASCE, Denver, Colorado. 1994.

LABADIE, J. W. Optimal operation of multireservoir systems: State-of-the-art review. Journal of Water Resources, v.130, n.2, p.93-111, 2004.

LAW, J.; BROWN, M.; Development of a Large Network Model to Evaluate Yield of Proposed Reservoir. Computerizeddecisionsupport systems for water managers, $p, 621-631,1989$.

LIMA, G. Aplicação de simulação computacional na análise de conflitos entre os usos múltiplos da água na bacia do rio Atibaia no Estado de São Paulo. Dissertação (Mestrado) -Escola de Engenharia de São Carlos, universidade de São Paulo. 2002, 129p.

MAIA, A.G.; GRACIOSA, M.C.P.; LILLELA, S.M. OperRes - modelo de operação de reservatório em tempo real. In: VII Simpósio do Curso de Pós Graduação em Ciências da Engenharia Ambiental da EESC-USP, São Carlos, SP. 2001.

MOHAMMADI, B.; MARIÑO, M.A. Reservoir operation: Choice of objective Functions. Journal of water resources planning and management, v.110, n.1, p.15-29, 1984.

MOHAN, S.; RAIPURE, D.M. Multiobjetive analysis of multireservoir system. Journal of water resources planning and Management, v.118, n.4, p.356-370, 1992.

PEIXOTO, L. S. A utilização de simulação computacional no gerenciamento de usos múltiplos da água na bacia do Sapucaí/grande no Estado de São Paulo. Dissertação (mestrado) Escola de Engenharia de São Carlos, Universidade de São Paulo. 2002, 131p.

SANTA CATARINA. Estudo dos instrumentos de gestão de recursos hídricos para o Estado de Santa Catarina a apoio para sua implementação. Regionalização de vazões das bacias hidrográficas estaduais do estado de Santa Catarina. V.1. 2006. 143p.

SILVA, I.N.; OLIVEIRA, J.B.; FONTES, L.O.; ARRAES, F.D.D. Distribuição de frequências da chuva para a região Centro-Sul do Ceará, Brasil. Revista Ciência Agronômica, v.44, n.3, p.481-487, 2013.

TUCCI, C.E.M. Modelos hidrológicos. Editora Universidade/UFRGS, ABRH. Porto Alegre. 1988.

UGGIONI, A.B.; BACK, Á.J. Utilização da modelagem matemática no planejamento ambiental do litoral sul de Santa Catarina. Revista de Tecnologia e Ambiente, v.11, p.23-55, 2005.

Van OEL, P. R. KROL, M. S. HOEKSTRA, A. Y. ARAÚJO, J. C. The impact of upstream water abstractions on reservoir yield: the case of the Orós Reservoir in Brazil. Hydrological Sciences Journal-des Sciences Hydrologiques, v.53, n.4, p.857-867. 2008. 
WURBS, R.A. Reservoir-System Simulation and Optimizations Models. Journal of Water Planning and Management, v.119, n.4, p.455-472, 1993.

YEH, W.G. Reservoir Management and Operations Models: A state-of-the art Review. Water Resources Research, v.21, n.12, p.1797-1818, 1985.

Juliano Possamai Della Engenharia Civil, Universidade do extremo Sul Catarinense (Unesc). E-mail: julianodella@gmail.com.

Álvaro José Back Programa de Pós-graduação em Ciências Ambientais (PPGCA/Unesc), Universidade do Extremo Sul Catarinense (Unesc). E-mail: ajb@unesc.net. 